\title{
¿LA MONOTORIZACIÓN DE LA TEMPERATURA CORPORAL ES LICITA TOMARLA EN ESPAÑA EN LA ÉPOCA POSPANDEMIA?: UN BREVE ESTUDIO DESDE LA LEY DE PROTECCIÓN DE DATOS Y, EL REGLAMENTO EUROPEO
}

\author{
IS MONOTORIZATION OF BODY TEMPERATURE BILLY TO TAKE IN SPAIN IN THE POST- \\ PANDEMIC TIME?: A BRIEF STUDY FROM THE DATA PROTECTION LAW AND THE \\ EUROPEAN REGULATION
}

\begin{abstract}
Salvador Morales Ferrer
Doctor en Derecho por el programa de Estudios Jurídicos, Ciencia Política y Criminología de la Universidad de Valencia, con la calificación Apto Cum Laude. Doctor Honoris Causa por el Claustro Nacional de Doctores de México (Unam). Certificado-Diploma de Estudios Avanzados TERCER CICLO - DOCTORADO por la Universidad Cardenal Herrera CEU de Valencia. Certificado de Aptitud Profesional realizado en la Escuela de Práctica Jurídica del Ilustre Colegio de abogados de Alzira. Máster Propio en Mediación y Gestión Eficiente de Conflictos por la Universidad Cardenal Herrera-Ceu (Valencia). Certificado de Aptitud Pedagógica por la Universidad de Valencia. Miembro del ILUSTRE COLEGIO DE ABOGADOS DE ALZIRA.

E-mail: salvadormorales@icaalzira.com
\end{abstract}

Convidado

RESUMEN: En este Siglo XXI, el azote del Covid-19 es global, lo que implica que muchos países de Europa, en especial en España donde ha habido muchos fallecimientos a causa de la pandemia, lo que implica que se ha vuelto a la nueva normalidad, pero no atendiendo a los parámetros anteriores de la pandemia. Por lo que, el Gobierno Español a promulgado diversas medidas entre ellas la toma de temperatura en los aeropuertos, puertos ante la apertura de fronteras y, la llegada de turistas, aunque se excluye esto último del Reglamento Europeo de Protección de Datos, pero no el formulario a la entrada en España. Por otro lado, están los las grandes superficies comerciales que sin previo consentimiento del cliente monitorizan la temperatura del cliente contraviniendo el Reglamento Europeo de Protección de Datos y, la Ley Orgánica de Protección de Datos incluso la propia Constitución Española. Por otra parte, están los trabajadores y trabajadoras que previo comunicado del empleador se les monitoriza para entrar en sus puestos de trabajo, así como los centros oficiales del Estado, Centros Autonómicos, por lo cual estos en última instancia pueden los ciudadanos y ciudadanas suprimir los datos automatizados de ellos.

Palabras Claves: Protección ante la Covid-19; Trabajadores; Centros no oficiales; Centros Oficiales; Turistas.

ABSTRACT: In this 21st century, the scourge of Covid-19 is global, which implies that many countries in Europe, especially in Spain where there have been many deaths due to the pandemic, which implies that it has returned to the new normality, but not taking into account the previous parameters of the pandemic. Therefore, the Spanish Government has enacted various measures, including temperature taking at airports, ports in the face of opening borders, and the arrival of 
tourists, although the latter is excluded from the European Data Protection Regulation, but not the form upon entry into Spain. On the other hand, there are the large commercial areas that, without the prior consent of the client, monitor the client's temperature in contravention of the European Data Protection Regulation and, the Organic Law on Data Protection, including the Spanish Constitution itself. On the other hand, there are the workers who, prior to the employer's communication, are monitored to enter their jobs, as well as the official centers of the State, Autonomous Centers, so that ultimately these citizens can suppress the automated data from them.

Keywords: Protection against Covid-19, Workers, Unofficial Centers, Official Centers, Tourists.

SUMÁRIO: Introducción. I. El principio fundamental sobre el tratamiento de las camaras térmicas. II. ¿Que entidades pueden utilizar la monitorización de la temperatura a los ciudadanos y las ciudanadas?.III. El principio de legalidad de la monitorización de la temperatura en distintos ámbitos de deambulación de las personas y en especial en el ámbito laboral. IV. Las garantias de las personas monotorizadas en la protección de datos y el reglamento europeo. V. Los derechos de las personas monotorizadas en el reglamento europeo. VI. La toma de temperatura en las cámaras térmicas en el reglamento europeo, en los aeropuestos españoles tanto los viajeros españoles, así como los turistas extranjeros. VII. El fundamento juridico internacional y europeo para la aplicación de esta norma. VIII. El fundamento normativo de España ante el tráfico aereo y maritimo. Conclusiones. Referencias.

\section{INTRODUCCIÓN}

España, ha sido uno de los países más castigados por la pandemia del Covid-19, en Europa, por lo que atendiendo a la desescalada muchos centros públicos e, incluso laborales sean tomado la libertad de tomar la temperatura corporal tanto de sus ciudadanos y ciudadanas o, trabajadores y trabajadoras sin el previo consentimiento de estos, lo que implicaría una intromisión al derecho a la intimidad, al respecto cabe mencionar la Constitución Española de $1978{ }^{1}$ que en su artículo 18 apartado 1 señala: "Se garantiza el derecho a la intimidad y la propia imagen", por lo que este sistema de cámaras de monitorización se adaptarán a la presunta imagen de la persona y, toma de temperatura de la persona en cuestión quedando estos datos en ficheros, tanto de la empresa o ,centros públicos siempre que no tengan permiso de sanidad o, las distintas Conserjerías de Sanidad de la Comunidades Autónomas, por lo que deberán contar los plazos de conservación como indica Reglamento Europeo de Protección de Datos ${ }^{2}$ en adelante el (RGPD), respecto a los turistas extranjeros que vienen a España la responsabilidad civil o, penal recaerá sobre el Ministerio de Sanidad Español, en el caso que hubiera un rebrote en las distintas Comunidades Autónomas Españolas. Con el presente artículo se pretende realizar un análisis descriptivo sobre los efectos jurídicos de protección ante el Covid-19, tanto en el ámbito de los comercios, empresas, entes oficiales o, viajes entre Comunidades Autónomas o, llegada de pasajeros del extranjero. El artículo tiene la siguiente estructura: el primero esboza como se trata a los ciudadanos y, ciudadanas ante las cámaras térmicas mediante el RGPD; el segundo presenta las entidades que pueden monitorizar a los ciudadanos y ciudadanas; el tercero muestra la legalidad de toma de temperatura de los trabajadores y, trabajadoras; ; el cuarto atiende a las garantías que ofrece a las personas en la Ley Orgánica de Protección de Datos Personales y garantía de derechos digitales en adelante

\footnotetext{
${ }^{1}$ Constitución Española y la Constitución Europea (2006). Edición Especial Consejo General de la Abogacía Española Editorial La Ley Madrid (Las Rozas). p.15

${ }^{2}$ Reglamento (UE) 2016/679 del Parlamento Europeo y del Consejo de 27 de abril de 2016 relativo a la protección de las personas físicas en lo que respecta al tratamiento de datos personales y a la libre circulación de estos datos y por el que se deroga la Directiva 95/46/CE. (Reglamento general de protección de datos) https://www.boe.es/doue/2016/119/L00001-0088.pdf
}

Revista de Direito Brasileira | Florianólopis, SC | v. 25 | n. 10 | p. 459-472 | Jan./Abr. 2020 
(LOPD) Española y el RGPD; el quinto aborda los derechos de las personas monitorizadas en la toma de temperatura en el RGPD; el sexto analiza la toma de temperatura en los aeropuertos españoles; el séptimo aclara el fundamento jurídico internacional y, europeo para la aplicación de la toma de temperatura; ; el octavo muestra el fundamento normativo sobre la aplicación en aeropuertos y puertos españoles

\section{EL PRINCIPIO FUNDAMENTAL SOBRE EL TRATAMIENTO DE LAS CAMARAS TÉRMICAS}

En este sentido, los datos personales que se registran la temperatura y, el rostro de las personas deberán ser tratados según lo que enuncia el Reglamento Europeo de Protección de Datos en adelante (RGPD) $)^{3}$ en su artículo 5.1 que señala : “ Los datos personales serán: a) tratados de manera lícita, leal y transparente en relación con el interesado («licitud, lealtad y transparencia»); c) adecuados, pertinentes y limitados a lo necesario en relación con los fines para los que son tratados («minimización de datos»); d) exactos y, si fuera necesario, actualizados; se adoptarán todas las medidas razonables para que se supriman o rectifiquen sin dilación los datos personales que sean inexactos con respecto a los fines para los que se tratan («exactitud»); e) mantenidos de forma que se permita la identificación de los interesados durante no más tiempo del necesario para los fines del tratamiento de los datos personales; los datos personales podrán conservarse durante períodos más largos siempre que se traten exclusivamente con fines de archivo en interés público, fines de investigación científica o histórica o fines estadísticos, de conformidad con el artículo 89, apartado 1, sin perjuicio de la aplicación de las medidas técnicas y organizativas apropiadas que impone el presente Reglamento a fin de proteger los derechos y libertades del interesado («limitación del plazo de conservación»); f) tratados de tal manera que se garantice una seguridad adecuada de los datos personales, incluida la protección contra el tratamiento no autorizado o ilícito y contra su pérdida, destrucción o daño accidental, mediante la aplicación de medidas técnicas u organizativas apropiadas («integridad y confidencialidad»)", del mismo modo cabe mencionar la Carta Europea de Derechos Fundamentales de la Unión Europea ${ }^{4}$ que en su artículo 8.1 señala: "Toda persona tiene derecho a la protección de los datos de carácter personal que le conciernan", al hilo cabe mencionar el Tribunal Supremo de España ${ }^{5}$ que analiza el Derecho a la intimidad así cabe citar sus Fundamentos de Derecho Segundo párrafo 1 que señala:" Por suerte, que el derecho fundamental a la intimidad personal otorga a su titular cuando menos una facultad negativa o de exclusión, que impone a terceros el deber de abstención de intromisiones, salvo que estén fundadas en una previsión legal que tenga justificación constitucional y que sea proporcionada, o que exista un consentimiento eficaz del afectado que lo autorice, pues corresponde a cada persona acotar el ámbito de intimidad personal que reserva al conocimiento ajeno", del mismo modo cabe citar entre la doctrina al autor Prieto ${ }^{6}$ que menciona: "El proveedor de un servicio de comunicaciones electrónicas disponible para el público deberá adoptar las medidas técnicas y de gestión adecuadas para preservar la seguridad de sus servicios, teniendo en cuenta que dichas medidas garantizarán un nivel de seguridad adecuado al riesgo existente", por lo

\footnotetext{
${ }^{3}$ Reglamento (UE) 2016/679 del Parlamento Europeo y del Consejo de 27 de abril de 2016 relativo a la protección de las personas físicas en lo que respecta al tratamiento de datos personales y a la libre circulación de estos datos y por el que se deroga la Directiva 95/46/CE.pps.L119/35-L 119/36. (Reglamento general de protección de datos) https://www.boe.es/doue/2016/119/L00001-0088.pdf

4 Carta Europea de Derechos Fundamentales de la Unión Europea (30/03/2012) D.O.U.E. p. C/83/393.www.boe.es>doue

${ }^{5}$ Tribunal Supremo (Sala Primera de lo Civil) (Ponente: Vela Torres, Pedro José) (sentencia 485/2016 de 14/ de julio) Rec.1805/2015. LA LEY 82421/2016.

${ }^{6}$ Prieto Andrés, Antonio (2002). "La nueva Directiva europea sobre tratamiento de datos personales y la protección a la intimidad en el sector de las telecomunicaciones". Diario La Ley No 5620 (Tomo 5), Año XXIII. Editorial La Ley Madrid (Las Rozas). p.1711.
}

Revista de Direito Brasileira | Florianólopis, SC | v. 25 | n. 10 | p. 459-472 | Jan./Abr. 2020 
cual serán aplicadas con el consentimiento del Ministerio de Sanidad y, adoptando el consentimiento siempre del ciudadano o, ciudadana afectada.

\section{II. ¿QUE ENTIDADES PUEDEN UTILIZAR LA MONITORIZACIÓN DE LA TEMPERATURA A LOS CIUDADANOS Y LAS CIUDANADAS?}

Al respecto, cabe mencionar el RGPD en su artículo $89^{7}$ párrafo 1 que señala: "El tratamiento con fines de archivo en interés público, fines de investigación científica o histórica o fines estadísticos estará sujeto a las garantías adecuadas, con arreglo al presente Reglamento, para los derechos y las libertades de los interesados. Dichas garantías harán que se disponga de medidas técnicas y organizativas, en particular para garantizar el respeto del principio de minimización de los datos personales. Tales medidas podrán incluir la seudonimización, siempre que de esa forma puedan alcanzarse dichos fines. Siempre que esos fines pueden alcanzarse mediante un tratamiento ulterior que no permita o ya no permita la identificación de los interesados, esos fines se alcanzarán de ese modo". Por lo cual, podrán utilizar estas cámaras de monitorización de temperatura, centros hospitalarios o, que dependan de sanidad o, entes oficiales siempre que tengan permiso del Ministerio de Sanidad u, entes autonómicos de Sanidad. Por lo que, se debe atenderse a la información mediante el principio de transparencia, como menciona el RGPD $^{8}$ en su Considerando 58: "El principio de transparencia exige que toda información dirigida al público o al interesado sea concisa, fácilmente accesible y fácil de entender, y que se utilice un lenguaje claro y sencillo, y, además, en su caso, se visualice. Esta información podría facilitarse en forma electrónica. Ello es especialmente pertinente en situaciones en las que la proliferación de agentes y la complejidad tecnológica de la práctica hagan que sea difícil para el interesado saber y comprender si se están recogiendo, por quién y con qué finalidad, datos personales que le conciernen, como es en el caso de la publicidad en línea", por lo cual, se puede aplicar a los ayuntamientos o, entes oficiales que estén autorizados por Sanidad por lo que pueden encontrar una persona que tenga en este momento la temperatura corporal elevada y, le realizan un Pcr, o. prueba serológica del Covid-19 por lo que, le pueden diagnosticar la infección del Covid-19 y, después lo trasladan al hospital y, deberán comunicarlo al interesado, sobre la toma de temperatura mediante un medio electrónico personal, como tal debe ajustarse a las previsiones de la legislación vigente, por lo que es muy importante mencionar el RGPD 9 en su Considerando 50 que señala: “ Si el tratamiento es necesario para el cumplimiento de una misión realizada en interés público o en el ejercicio de poderes públicos conferidos al responsable del tratamiento, los cometidos y los fines para los cuales se debe considerar compatible y lícito el tratamiento ulterior se pueden determinar y especificar de acuerdo con el Derecho de la Unión o de los Estados miembros. Las operaciones de tratamiento ulterior con fines de archivo en interés público, fines de investigación científica e histórica o fines estadísticos deben considerarse operaciones de tratamiento lícitas compatibles. Con objeto de determinar si el fin del tratamiento ulterior es compatible con el fin de la recogida inicial de los datos personales, el responsable del tratamiento, tras haber cumplido todos los requisitos para la

\footnotetext{
${ }^{7}$ Reglamento (UE) 2016/679 del Parlamento Europeo y del Consejo de 27 de abril de 2016 relativo a la protección de las personas físicas en lo que respecta al tratamiento de datos personales y a la libre circulación de estos datos y por el que se deroga la Directiva 95/46/CE.pps.L119/84-L 119/85. (Reglamento general de protección de datos) https://www.boe.es/doue/2016/119/L00001-0088.pdf

${ }^{8}$ Reglamento (UE) 2016/679 del Parlamento Europeo y del Consejo de 27 de abril de 2016 relativo a la protección de las personas físicas en lo que respecta al tratamiento de datos personales y a la libre circulación de estos datos y por el que se deroga la Directiva 95/46/CE.p. L119/11. (Reglamento general de protección de datos) https://www.boe.es/doue/2016/119/L00001-0088.pdf

${ }^{9}$ Reglamento (UE) 2016/679 del Parlamento Europeo y del Consejo de 27 de abril de 2016 relativo a la protección de las personas físicas en lo que respecta al tratamiento de datos personales y a la libre circulación de estos datos y por el que se deroga la Directiva 95/46/CE.pps.L119/9-L119-10. (Reglamento general de protección de datos) https://www.boe.es/doue/2016/119/L00001-0088.pdf
}

Revista de Direito Brasileira | Florianólopis, SC | v. 25 | n. 10 | p. 459-472 | Jan./Abr. 2020 
licitud del tratamiento original, debe tener en cuenta, entre otras cosas, cualquier relación entre estos fines y los fines del tratamiento ulterior previsto, el contexto en el que se recogieron los datos, en particular las expectativas razonables del interesado basadas en su relación con el responsable en cuanto a su uso posterior, la naturaleza de los datos personales, las consecuencias para los interesados del tratamiento ulterior previsto y la existencia de garantías adecuadas tanto en la operación de tratamiento original como en la operación de tratamiento ulterior prevista". Por tanto, mediante los Poderes Públicos en este caso el Ministerio de Sanidad garantizará estás medidas a los entes sanitarios de salud de las Comunidades Autónomas en este caso se debe hacerse referencia a la Constitución Española de $1978^{10}$ en su artículo 148 párrafo 1 apartado 21 que señala: "La Comunidades Autónomas podrán asumir las competencias en las siguientes materias: "Sanidad", al hilo cabe mencionar la Sentencia del Tribunal Supremo de España ${ }^{11}$ que señala en su Fundamento de Derecho Quinto b : "cada Comunidad Autonómica que posea competencia en materia legislativa sanitaria puede establecer medias en de desarrollo legislativo", exceptuando las ciudades de Ceuta y Melilla , cuya competencia dependerán del Ministerio de Sanidad. Por otro lado, cabe citar la Sentencia del Tribunal Supremo de España ${ }^{12}$ en sus Fundamentos de Derecho Tercero que menciona: "Cita los artículos 149.1.16 de la Constitución( Sanidad exterior, bases de sanidad interior, coordinación general de la sanidad y planificación, alta inspección y legislación sobre productos sanitarios como competencias exclusivas del Estado) y 148.1.21 ${ }^{\circ}$ (competencia autonómica en materia de sanidad e higiene en los términos que establezca el respectivo Estatuto de Autonomía). De este precepto se desprende que la competencia sobre la gestión y control de los Servicios de Salud puede ser recogida por las Comunidades Autónomas mediante su inclusión en los Estatutos de Autonomía, con independencia de que la competencia haya sido efectivamente transferida". Por otro lado, en la doctrina española en este caso cabe mencionar al autor Salvador ${ }^{13}$ que señala: "De acuerdo con lo allí previsto al Estado le corresponde: La "sanidad exterior" que incluye todas las actividades que "se realicen en materia de vigilancia y control de los posibles riesgos para la salud derivados de la importación, exportación o tránsito de mercancías y del tráfico internacional de viajeros". Por lo que, se entiende que la Sanidad Exterior en la Comunidades Autónomas dependerán del Gobierno, aunque estas la auxiliarán en el tráfico de viajeros frente la pandemia del Covid-19.

\section{EL PRINCIPIO DE LEGALIDAD DE LA MONITORIZACIÓN DE LA TEMPERATURA EN DISTINTOS ÁMBITOS DE DEAMBULACIÓN DE LAS PERSONAS Y EN ESPECIAL EN EL ÁMBITO LABORAL}

En este sentido, como todo tratamiento de datos, la recogida por medio de la monitorización de la temperatura de la persona se entiende que debe de regirse por el RGPD, con base a su legitimación por lo que, se debe atender al artículo $6.1^{14}$ de la norma que señala: "El tratamiento solo será lícito si se cumple al menos una de las siguientes condiciones: a) el interesado dio su consentimiento para el tratamiento de sus datos personales para uno o varios fines

\footnotetext{
${ }^{10}$ Constitución Española y la Constitución Europea (2006). Op. Cit., pps.56-57.

${ }^{11}$ Tribunal Supremo (Sala Tercera de lo Contencioso-administrativo, Sección 4a) (Ponente: Menéndez Pérez, Segundo) (Sentencia de 10 de enero de 2012). Rec. 5243/2006. LA LEY463/2012

${ }^{12}$ Tribunal Supremo (Sala Tercera de lo Contencioso-administrativo, Sección 4a) (Ponente: Xiol Ríos, Juan Antonio) (Sentencia de 27 de enero de 2003). Rec.388/2000. LA LEY 1114/2003.

13 Salvador Sancho, Armando (1991). "Modalidades de ejercicio de la Competencia Estatal en Materia de Sanidad Exterior (Participación en la misma de las Comunidades Autónomas: Sentencia 252/88). Revista de Estudios de la Administración Local y Autonómica. Editorial INAP Madrid. p.196.

${ }^{14}$ Reglamento (UE) 2016/679 del Parlamento Europeo y del Consejo de 27 de abril de 2016 relativo a la protección de las personas físicas en lo que respecta al tratamiento de datos personales y a la libre circulación de estos datos y por el que se deroga la Directiva 95/46/CE.pps.L119/36 (Reglamento general de protección de datos) https://www.boe.es/doue/2016/119/L00001-0088.pdf
}

Revista de Direito Brasileira | Florianólopis, SC | v. 25 | n. 10 | p. 459-472 | Jan./Abr. 2020 
específicos; d) el tratamiento es necesario para proteger intereses vitales del interesado o de otra persona física; e) el tratamiento es necesario para el cumplimiento de una misión realizada en interés público o en el ejercicio de poderes públicos conferidos al responsable del tratamiento". Por tanto, esta medida de comprobación monitorizada de la temperatura corporal, no puede realizase el consentimiento a efectos generales de las personas trabajadoras, por lo que estas no pueden negarse, sin poder entrar en sus puestos de trabajo o, centros educativos, comerciales y donde pueden deambular, por lo cual, este requisito no sería con plena libertad, que es uno de los requisitos de la base que legitima el $\mathrm{RGPD}^{15}$ puesto como manifiesta en su artículo $9 \mathrm{~g}$ : "el tratamiento es necesario por razones de un interés público esencial, sobre la base del Derecho de la Unión o de los Estados miembros, que debe ser proporcional al objetivo perseguido, respetar en lo esencial el derecho a la protección de datos y establecer medidas adecuadas y específicas para proteger los intereses y derechos fundamentales del interesados", al hilo cabe mencionar la Orden SND/518/2020, de 11 de junio, por la que se regula la autorización de un programa piloto de apertura de corredores turísticos seguros en la Comunidad Autónoma de Illes Balears mediante el levantamiento parcial de los controles temporales en las fronteras interiores establecidos con motivo de la situación de crisis sanitaria ocasionada por el COVID-19 ${ }^{16}$, que señala en su artículo 1: "Esta orden tiene por objeto regular la puesta en marcha, a partir del 15 de junio de 2020, de programas piloto para el establecimiento de corredores turísticos seguros hacia la Comunidad Autónoma de Illes Balears, mediante el levantamiento parcial de los controles temporales en las fronteras interiores. A estos efectos, se permitirá, desde esa fecha, la entrada de turistas a la citada comunidad autónoma, procedentes de Estados miembros o Estados asociados Schengen, a través de rutas aéreas específicas. La identificación de estas rutas aéreas”, por lo cual se puede realizar la previa monitorización a los turistas que provienen del espacio Schengen. Por otro lado, también es muy importante la toma de temperatura mediante monitorización de los trabajadores y trabajadoras, siempre tengan comunicación expresa mediante escrito por el empleador, para garantizar el empleador la la seguridad y la salud de sus trabajadores y trabajadoras que están a su cargo, por medio de una base que sea garantista jurídicamente, por lo cual permitiría el tratamiento de la salud y legitimaría este tratamiento, al hilo cabe citar el RGPD $^{17}$ en su artículo 4.11 que señala: "«consentimiento del interesado»: toda manifestación de voluntad libre, específica, informada e inequívoca por la que el interesado acepta, ya sea mediante una declaración o una clara acción afirmativa, el tratamiento de datos personales que le conciernen". Por otra parte, el autor López ${ }^{18}$ es muy crítico con el consentimiento de los trabajadores al mencionar: "cuestión que introduce un sutil matiz diferenciador con la consideración como dato de los identificadores, cuya información es dudosa o, trabajadores del responsable asocien a una persona física”. Por tanto, esta situación es dudosa por la conservación de los ficheros personales automatizados.

\footnotetext{
${ }^{15}$ Reglamento (UE) 2016/679 del Parlamento Europeo y del Consejo de 27 de abril de 2016 relativo a la protección de las personas físicas en lo que respecta al tratamiento de datos personales y a la libre circulación de estos datos y por el que se deroga la Directiva 95/46/CE.p. L119/34 (Reglamento general de protección de datos) https://www.boe.es/doue/2016/119/L00001-0088.pdf

${ }_{16}$ Orden SND/518/2020, de 11 de junio, por la que se regula la autorización de un programa piloto de apertura de corredores turísticos seguros en la Comunidad Autónoma de Illes Balears mediante el levantamiento parcial de los controles temporales en las fronteras interiores establecidos con motivo de la situación de crisis sanitaria ocasionada por el COVID-19. I. Disposiciones Generales. Ministerio de Sanidad. Boletín Oficial del Estado (BOE) Madrid. N. Boletín 165 p.39567 BOE-A-2020-6024. www.boe.es>Buscar

${ }^{17}$ Reglamento (UE) 2016/679 del Parlamento Europeo y del Consejo de 27 de abril de 2016 relativo a la protección de las personas físicas en lo que respecta al tratamiento de datos personales y a la libre circulación de estos datos y por el que se deroga la Directiva 95/46/CE.p. L119/38 (Reglamento general de protección de datos) https://www.boe.es/doue/2016/119/L00001-0088.pdf

18 López Calvo, José (2017) “Comentarios al Reglamento Europeo de Protección de Datos”. Editorial Jurídica Sepín Las Rozas (Madrid). p.179
}

Revista de Direito Brasileira | Florianólopis, SC | v. 25 | n. 10 | p. 459-472 | Jan./Abr. 2020 


\section{LAS GARANTIAS DE LAS PERSONAS MONOTORIZADAS EN LA PROTECCIÓN DE DATOS Y EL REGLAMENTO EUROPEO}

De esta forma, cabe mencionar la Ley Orgánica de Protección de Datos Personales y garantía de derechos digitales (LOPD) Española que señala ${ }^{19}$ en su artículo $1^{\text {o: }}$ "la protección de las personas físicas en lo que respecta al tratamiento de sus datos personales", al hilo cabe mencionar la Sentencia del Tribunal Supremo ${ }^{20}$ que señala en sus racionamientos jurídicos segundo: "las garantías en la protección de los derechos de los ciudadanos", por lo que además los ciudadanos españoles que van a viajar a distintos sitios de España o al, extranjero e incluso turistas extranjeros que viene ahora a España siguen teniendo sus garantías en la RGPD como menciona el autor Fernández ${ }^{21}$ : “ La Agencia Española de Protección DE DATOS (AEPD) concluye que los sistemas generales de cifrado son insuficientes para el intercambio de información con las garantías que se precisan en el Reglamento para un uso profesional'. Por lo que, AEPD, no está muy de acuerdo en la implantación de los sistemas de monitorización de la temperatura personal en los aeropuertos españoles. Por otro lado, siguiendo con la RGPD, establece de acorde con la aplicación de las demás garantías, que el Reglamento establece, si bien adaptadas a las condiciones y tratamiento y circunstancias específicas de este tipo de tratamiento, de esta forma cabe mencionar la RGPD en su Considerando $50^{22}$ que manifiesta: “El tratamiento de datos personales con fines distintos de aquellos para los que hayan sido recogidos inicialmente solo debe permitirse cuando sea compatible con los fines de su recogida inicial. En tal caso, no se requiere una base jurídica aparte, distinta de la que permitió la obtención de los datos personales. Si el tratamiento es necesario para el cumplimiento de una misión realizada en interés público o en el ejercicio de poderes públicos conferidos al responsable del tratamiento, los cometidos y los fines para los cuales se debe considerar compatible y lícito el tratamiento ulterior se pueden determinar y especificar de acuerdo con el Derecho de la Unión o de los Estados miembros. Las operaciones de tratamiento ulterior con fines de archivo en interés público, fines de investigación científica e histórica o fines estadísticos deben considerarse operaciones de tratamiento lícitas compatibles. La base jurídica establecida en el Derecho de la Unión o de los Estados miembros para el tratamiento de datos personales también puede servir de base jurídica para el tratamiento ulterior. Con objeto de determinar si el fin del tratamiento ulterior es compatible con el fin de la recogida inicial de los datos personales, el responsable del tratamiento, tras haber cumplido todos los requisitos para la licitud del tratamiento original, debe tener en cuenta, entre otras cosas, cualquier relación entre estos fines y los fines del tratamiento ulterior previsto, el contexto en el que se recogieron los datos, en particular las expectativas razonables del interesado basadas en su relación con el responsable en cuanto a su uso posterior, la naturaleza de los datos personales, las consecuencias para los interesados del tratamiento ulterior previsto y la existencia de garantías adecuadas tanto en la operación de tratamiento original como en la operación de tratamiento ulterior prevista". Por tanto, el responsable del tratamiento de datos será el Ministerio de Sanidad que, a su vez, le serán conferidos a las autoridades sanitarias autonómicas solamente para la atención de los pacientes españoles que viajan o, extranjeros comunitarios que tengan convenios con España como

\footnotetext{
${ }^{19}$ Ley Orgánica 3/2018, de 5 de diciembre de Protección de Datos Personales y garantía de derechos digitales. Boletín Oficial del Estado (BOE) Madrid. N. Boletín 294.p.119800. http: //www.boe.es>buscar/act. docphp?id=BOE-A-201816673

${ }^{20}$ Tribunal Supremo (Sala Tercera de lo Contencioso-administrativo, Sección 1ª) (Ponente: Román García, Fernando) (Auto del 15 de noviembre 2019). Rec.4739/2019. LA LEY 161731/2019

${ }^{21}$ Fernández Burgueño, Pablo (2017) $\left(\mathrm{N}^{\circ} 3\right)$ "La obligación de cifrado de la información en el Reglamento de Protección de datos" Editorial Woters Klumer. La Ley Las Rozas (Madrid). p.3

${ }^{22}$ Reglamento (UE) 2016/679 del Parlamento Europeo y del Consejo de 27 de abril de 2016 relativo a la protección de las personas físicas en lo que respecta al tratamiento de datos personales y a la libre circulación de estos datos y por el que se deroga la Directiva 95/46/CE.p. L119/9-L119/10 (Reglamento general de protección de datos) https://www.boe.es/doue/2016/119/L00001-0088.pdf
}

Revista de Direito Brasileira | Florianólopis, SC | v. 25 | n. 10 | p. 459-472 | Jan./Abr. 2020 
menciona la Constitución Española de $1978^{23}$ en su artículo $148.1^{\circ}$ párrafo 21 que menciona: "Sanidad". Por otra parte, en atención a la pospandemia tendrán las autoridades sanitarias españolas o, sus directores de sanidad la facultad de cancelar, rectificar o, suprimir estos datos de los ficheros aeroportuarios de la Sanidad Exterior.

\section{LOS DERECHOS DE LAS PERSONAS MONOTORIZADAS EN EL REGLAMENTO EUROPEO}

Por lo que, es importante establecer plazos y criterios de conservación de los datos registrados. En principio y dadas las finalidades del tratamiento, este registro de conservación no debería producirse, salvo que puede justificarse suficientemente ante la necesidad de hacer frente a eventuales acciones legales derivadas de la denegación de acceso tanto a los ciudadanos nacionales, así como a los turistas extranjeros que vienen a España de vacaciones. Por tanto, sobre la conservación y los plazos es muy explícito el $\mathrm{RGPD}^{24}$ en su artículo 12.3 al señalar: "El responsable del tratamiento facilitará al interesado información relativa a sus actuaciones sobre la base de una solicitud y, en cualquier caso, en el plazo de un mes a partir de la recepción de la solicitud. Dicho plazo podrá prorrogarse otros dos meses en caso necesario, teniendo en cuenta la complejidad y el número de solicitudes. El responsable informará al interesado de cualquiera de dichas prórrogas en el plazo de un mes a partir de la recepción de la solicitud, indicando los motivos de la dilación. Cuando el interesado presente la solicitud por medios electrónicos, la información se facilitará por medios electrónicos cuando sea posible, a menos que el interesado solicite que se facilite de otro modo". Por lo cual, la persona interesada tendrá que interponer un escrito al responsable de los datos que al respecto será la autoridad de sanidad exterior donde corresponda el aeropuerto, respecto a su Comunidad Autónoma, acogiéndose a un mes en el momento de la recepción del escrito. Por otro lado, el $\mathrm{RGPD}^{25}$ en su artículo 12. 5.b manifiesta: "Cuando las solicitudes sean manifiestamente infundadas o excesivas, especialmente debido a su carácter repetitivo, el responsable del tratamiento podrá: negarse a actuar respecto de la solicitud", al hilo cabe mencionar la Sentencia del Tribunal Supremo ${ }^{26}$ en su Fundamento de Derecho Primero manifiesta:“ ante la Agencia Española de Protección de datos (en adelante, AEPD), no le había dado acceso a sus datos personales dentro del plazo de un mes, tal como es legalmente exigido Como consecuencia de estos hechos, la resolución de la AEPD de 18 de octubre de 2004 estimó fundada la reclamación y declaró que había incumplido el deber legal de darle acceso a sus datos personales en el plazo de un mes". Por lo tanto, las personas interesadas deberán emprender acciones judiciales ante en encargado de los ficheros automatizados realizados en los distintos aeropuertos españoles. Sin embargo, dependiendo del tipo de tecnología, que se emplee, en los aeropuertos, puede ser necesario tomar en consideraciones otros elementos, que aunque relacionados con los mismos, tienen en una $\mathrm{u}$, otra diferente tecnología es un claro ejemplo como la toma de temperatura no monitorizada por otros medios, así como la pistolas de toma de temperatura a distancia, por la cual la persona no está monitorizada y, simplemente realizará

\footnotetext{
${ }^{23}$ Constitución Española y la Constitución Europea (2006). Op. Cit., p.49.

${ }^{24}$ Reglamento (UE) 2016/679 del Parlamento Europeo y del Consejo de 27 de abril de 2016 relativo a la protección de las personas físicas en lo que respecta al tratamiento de datos personales y a la libre circulación de estos datos y por el que se deroga la Directiva 95/46/CE.p. L119/40 (Reglamento general de protección de datos) https://www.boe.es/doue/2016/119/L00001-0088.pdf

${ }^{25}$ Reglamento (UE) 2016/679 del Parlamento Europeo y del Consejo de 27 de abril de 2016 relativo a la protección de las personas físicas en lo que respecta al tratamiento de datos personales y a la libre circulación de estos datos y por el que se deroga la Directiva 95/46/CE.p. L119/40 (Reglamento general de protección de datos) https://www.boe.es/doue/2016/119/L00001-0088.pdf

${ }^{26}$ Tribunal Supremo (Sala Tercera de lo Contencioso-administrativo, Sección 6 ${ }^{\text {a) }}$ ( Ponente: Díez Picazo Giménez, Luís María) ( Sentencia de 26 de enero de 2010) Rec.3371/2006.LA LEY431/2010
}

Revista de Direito Brasileira | Florianólopis, SC | v. 25 | n. 10 | p. 459-472 | Jan./Abr. 2020 
mediante un formulario que se rellena ante las autoridades sanitarias aeroportuarias comunitarias pero tendrá este formulario la misma efectividad ante la LOPD y ,el RGPD.

\section{LA TOMA DE TEMPERATURA EN LAS CÁMARAS TÉRMICAS EN EL REGLAMENTO EUROPEO, EN LOS AEROPUESTOS ESPAÑOLES TANTO LOS VIAJEROS ESPAÑOLES, ASÍ COMO LOS TURISTAS EXTRANJEROS}

En este sentido, como menciona la Resolución de 29 de junio de 2020, de la Dirección General de Salud Pública, Calidad e Innovación, relativa a los controles sanitarios a realizar en los puntos de entrada de España ${ }^{27}$, en su artículo 2 al señalar: "El control de temperatura se realizará de modo rutinario con el fin de identificar viajeros con fiebre. Se establece como límite de detección una temperatura igual o superior a $37,5^{\circ} \mathrm{C}$. La toma de la temperatura debe hacerse mediante termómetros sin contacto o por cámaras termográficas. No se almacenarán datos personales ni las imágenes captadas por las cámaras termográficas, debiendo garantizarse la privacidad del pasajero en todo momento". Por lo que, el Gobierno español hace caso a la AEPD, pero si se utilizará un formulario, como indica el artículo 4 de la misma norma ${ }^{28}$ al mencionar: "Las agencias de viaje, los operadores turísticos y las compañías de trasporte aéreo o marítimo y cualquier otro agente que comercialice billetes aisladamente o como parte de un viaje combinado, deberán informar a los pasajeros, en el inicio del proceso de venta de los billetes con destino a España, de la obligatoriedad de presentar el formulario de salud pública en el aeropuerto o puerto de destino. Así mismo, se avisará en el proceso de registro o check in de la obligatoriedad de presentar el formulario de salud pública a la llegada a España. Las compañías de transporte aéreo o marítimo una vez en espacio aéreo o marítimo español informarán a los pasajeros antes de llegar a su destino de la obligatoriedad de presentar el formulario de salud pública a la llegada, debiendo facilitar el formulario a los pasajeros que no hubieran podido cumplimentarlo por vía electrónica. Se establece un periodo transitorio, hasta el 31 de julio de 2020, en el que los pasajeros internacionales que no hayan podido cumplimentar telemáticamente el formulario de salud pública lo podrán presentar a su llegada a España en formato papel", por tanto como dice la norma con "la obligatoriedad de presentar el formulario de salud pública a la llegada a España”, por lo que el Ministerio de Sanidad Español deberán ser los responsables de asumir tanto la LOPD $^{29}$ así, como el RGPD ${ }^{30}$. Otro elemento a distinguir es lo que menciona la Resolución de 29 de junio de 2020, de la Dirección General de Salud Pública, Calidad e Innovación, relativa a los controles sanitarios a realizar en los puntos de entrada de España en su artículo $1{ }^{31}$ al señalar como uno de los elementos de entrada en España: "Todos los pasajeros que lleguen a España por vía aérea o marítima deberán someterse a un control

\footnotetext{
${ }^{27}$ Resolución de 29 de junio de 2020, de la Dirección General de Salud Pública, Calidad e Innovación, relativa a los controles sanitarios a realizar en los puntos de entrada de España I. Disposiciones generales. Ministerio de Sanidad Boletín Oficial del Estado (BOE) Madrid.181. p.45640. BOE-A-2020-6927.BOE.es www.boe,es $>$ Calendario $>01 / 07 / 2020$

${ }^{28}$ Resolución de 29 de junio de 2020, de la Dirección General de Salud Pública, Calidad e Innovación, relativa a los controles sanitarios a realizar en los puntos de entrada de España I. Disposiciones generales. Ministerio de Sanidad Boletín Oficial del Estado (BOE) Madrid.181. p.45641. BOE-A-2020-6927.BOE.es www.boe,es $>$ Calendario $>01 / 07 / 2020$

${ }^{29}$ Ley Orgánica 3/2018, de 5 de diciembre de Protección de Datos Personales y garantía de derechos digitales. Boletín Oficial del Estado (BOE) Madrid. N. Boletín 294. http: //www.boe.es>buscar/act. docphp?id=BOE-A-2018-16673

${ }^{30}$ Reglamento (UE) 2016/679 del Parlamento Europeo y del Consejo de 27 de abril de 2016 relativo a la protección de las personas físicas en lo que respecta al tratamiento de datos personales y a la libre circulación de estos datos y por el que se deroga la Directiva 95/46/CE. (Reglamento general de protección de datos) https://www.boe.es/doue/2016/119/L00001-0088.pdf

${ }^{31}$ Resolución de 29 de junio de 2020, de la Dirección General de Salud Pública, Calidad e Innovación, relativa a los controles sanitarios a realizar en los puntos de entrada de España I. Disposiciones generales. Ministerio de Sanidad. Boletín Oficial del Estado (BOE) Madrid.181. p.4564o. BOE-A-2020-6927.BOE.es www.boe,es $>$ Calendario $>01 / 07 / 2020$
}

Revista de Direito Brasileira | Florianólopis, SC | v. 25 | n. 10 | p. 459-472 | Jan./Abr. 2020 
sanitario un control visual sobre el estado del pasajero", me parece poco lógico desde el punto de vista de los conocimientos médicos entre otros elementos como el control visual de pasajero, por lo que, sería más efectivo el realizar al pasajero el Pcr en destino o, a la llegada al aeropuerto español, por tanto el legislador español dejo un poco peligroso la llegada de turistas de otros países e, incluso los pasajeros de España, estos últimos mediante el embarque por medios aéreos a otras Comunidades Autónomas.

\section{EL FUNDAMENTO JURIDICO INTERNACIONAL Y EUROPEO PARA LA APLICACIÓN DE ESTA NORMA}

Por lo que, mediante "La declaración sobre la segunda reunión del Comité de Emergencias del Reglamento Sanitario Internacional (2005) acerca del brote nuevo coronavirus (2019n- CoV) ${ }^{32}$ y, así se tomaron estas decisiones así cabe citar, El Reglamento Sanitario Internacional ${ }^{33}$, que menciona. "que colabore con los Estados Partes en el Reglamento Sanitario Internacional (2005), según proceda, incluso mediante la prestación o facilitación de cooperación técnica y apoyo logístico", por lo que la finalidad y alcance es prevenir la propagación internacional de enfermedades, proteger contra esa propagación, controlarla y darle una respuesta de salud pública proporcionada, al hilo relacionado con el Reglamento (UE) 2018/1139 del Parlamento Europeo y del Consejo ${ }^{34}$ en su punto 13 menciona: "La aplicación de principios problemáticos de gestión de la seguridad es esencial para la mejora continua de la seguridad de la aviación civil en la Unión, anticipando los riesgos de seguridad emergentes y haciendo el mejor uso de los recursos técnicos limitados. Por lo tanto, es necesario establecer un marco común para organizar e implementar acciones de mejora de la seguridad. Cada Estado miembro también debe elaborar un programa de seguridad del Estado. Ese programa debe ir acompañado de un plan que describa las acciones que debe tomar el Estado miembro para mitigar los riesgos de seguridad identificados". Por lo cual, lo Estados Miembros aplicarán las medidas que crean oportunas tanto, en el sector aéreo, así como en el marítimo.

\section{EL FUNDAMENTO NORMATIVO DE ESPAÑA ANTE EL TRÁFICO AEREO Y MARITIMO}

Por lo que, hay que acudir al Real Decreto-ley 23/2020, de 23 de junio, por el que se aprueban medidas en materia de energía y en otros ámbitos para la reactivación económica ${ }^{35}$ así cabe mencionar su Disposición adicional sexta. Control sanitario de los pasajeros internacionales que en su apartado 2 manifiesta: "En lo que se refiere al control documental, los pasajeros con origen en cualquier aeropuerto o puerto situado fuera del territorio español, deberán cumplimentar un formulario de salud pública. El contenido de dicho formulario y su forma de presentación será establecido por la persona titular de la Dirección General de Salud Pública, Calidad e Innovación del Ministerio de Sanidad", por lo que inicialmente solo se aplicaba un formulario dependiendo estrictamente del Ministerio de Sanidad, hasta que lo modifico la Resolución de 29 de junio de 2020, de la Dirección General de Salud Pública, Calidad e Innovación, relativa a los controles

\footnotetext{
${ }^{32}$ O.M.S. www.who.int $>$ Acceso $>$ Centro de prensa $>$ Detalles. p. 1

${ }^{33}$ Reglamento Sanitario Internacional (2008) Segunda edición. Editorial Organización Mundial de la Salud. Ginebra. Suiza.p.3

${ }^{34}$ Reglamento (UE) 2018/1139 del Parlamento Europeo y del Consejo (2018). Del 4 de julio. Diario de la Unión Europea. Bruselas. p. 212/1. https://www.easa.europa.eu/document-library/regulations/regulation-eu-20181139

${ }^{35}$ Real Decreto-ley 23/2020, de 23 de junio, por el que se aprueban medidas en materia de energía y en otros ámbitos para la reactivación económica. I. Disposiciones generales. Jefatura del Estado. Boletín Oficial del Estado (BOE) Madrid 175.p 4920. BOE-A-2020-6621-BOE.es. www.boe,es>Calendario >24/06/2020
}

Revista de Direito Brasileira | Florianólopis, SC | v. 25 | n. 10 | p. 459-472 | Jan./Abr. 2020 
sanitarios a realizar en los puntos de entrada de España ${ }^{36}$, en su artículo 2 al señalar: "El control de temperatura se realizará de modo rutinario con el fin de identificar viajeros con fiebre. Se establece como límite de detección una temperatura igual o superior a $37,5^{\circ} \mathrm{C}$. La toma de la temperatura debe hacerse mediante termómetros sin contacto o por cámaras termográficas", como se había mencionado anteriormente y, siguiendo con el Real Decreto-ley 23/2020, de 23 de junio, por el que se aprueban medidas en materia de energía y en otros ámbitos para la reactivación económica ${ }^{37}$ así cabe mencionar su Disposición adicional sexta. Control sanitario de los pasajeros internacionales en su apartado 3 manifiesta: "Si en el proceso del control sanitario se detecta que un pasajero puede padecer COVID-19 u otra patología que pueda suponer un riesgo para la salud pública, se realizará una evaluación médica en la que se valorarán los aspectos epidemiológicos y clínicos del pasajero. Si se confirma que el pasajero padece COVID-19 u otra patología que pueda suponer un riesgo para la salud pública, se activarán los protocolos establecidos para su derivación a un centro sanitario", por lo que el turista extranjero sea comunitario o, extracomunitario deberá tener un seguro de viaje para que le cubran estas patologías del Covid-19. ¿Al respecto que organismo debe colaborar con el Ministerio de Sanidad? Y en el punto $4^{38}$ de la norma es muy esclarecedor al mencionar: "En relación con la vía aérea, la implementación de los controles sanitarios El gestor aeroportuario y las compañías aéreas prestarán su colaboración al Ministerio de Sanidad para la implementación de estas medidas", al hilo cabe mencionar el Real Decreto-ley 21/2020, de 9 de junio, de medidas urgentes de prevención, contención y coordinación para hacer frente a la crisis sanitaria ocasionada por el COVID-19, ${ }^{39}$ que en su artículo 1 menciona: "El presente real decretoley tiene por objeto establecer las medidas urgentes de prevención, contención y coordinación necesarias para hacer frente a la crisis sanitaria ocasionada por el COVID-19, así como prevenir posibles rebrotes", por el cual el gobierno español implanta estas medidas y, como menciona artículo $17^{40}$ apartado 3 de la misma norma: "Los operadores de transporte aéreo y terrestre interprovinciales con número de asiento preasignado deberán recabar información para contacto de todos los pasajeros y conservar los listados un mínimo de cuatro semanas con posterioridad al viaje. Asimismo, deberán facilitar estos listados a las autoridades de salud pública cuando se requieran con la finalidad de realizar la trazabilidad de contactos", por lo que analógicamente se entiende primeramente que los turistas extranjeros o, nacionales tienen que tener los asientos de las aeronaves en su momento designadas, no el momento del embarque y, otro punto siguiente a tratar es que las aerolíneas deberán facilitar todos los listados de los pasajeros a las autoridades españolas. Puesto, desde el punto de vista competencial cabe mencionar la Constitución Española $^{41}$ en su artículo 149.1,16. a que señala: "El Estado tiene competencia exclusiva sobre las siguientes materias: Sanidad exterior”, por lo que será responsable el Ministerio de Sanidad, no las Comunidades Autónomas en ejercicio de sus competencias en el caso si hubiera un rebrote por

\footnotetext{
${ }^{36}$ Resolución de 29 de junio de 2020, de la Dirección General de Salud Pública, Calidad e Innovación, relativa a los controles sanitarios a realizar en los puntos de entrada de España I. Disposiciones generales. Ministerio de Sanidad Boletín Oficial del Estado (BOE) Madrid.181. p.45640. BOE-A-2020-6927.BOE.es www.boe,es $>$ Calendario $>01 / 07 / 2020$

${ }^{37}$ Real Decreto-ley 23/2020, de 23 de junio, por el que se aprueban medidas en materia de energía y en otros ámbitos para la reactivación económica. I. Disposiciones generales. Jefatura del Estado. Boletín Oficial del Estado (BOE) Madrid 175.p 4921 BOE-A-2020-6621-BOE.es. www.boe,es>Calendario>24/06/2020

${ }^{38}$ Real Decreto-ley 23/2020, de 23 de junio, por el que se aprueban medidas en materia de energía y en otros ámbitos para la reactivación económica. I. Disposiciones generales. Jefatura del Estado. Boletín Oficial del Estado (BOE) Madrid 175.p 4921 BOE-A-2020-6621-BOE.es. www.boe,es>Calendario>24/06/2020

${ }^{39}$ Real Decreto-ley 21/2020, de 9 de junio, de medidas urgentes de prevención, contención y coordinación para hacer frente a la crisis sanitaria ocasionada por el COVID-19. I. Disposiciones generales. Jefatura del Estado. Boletín Oficial del Estado (BOE) Madrid 163 p. 20.BOE-A-2020-5895-BOE.es (Legislación Consolidada). www.boe.es>Buscar.

${ }^{40}$ Real Decreto-ley 21/2020, de 9 de junio, de medidas urgentes de prevención, contención y coordinación para hacer frente a la crisis sanitaria ocasionada por el COVID-19. I. Disposiciones generales. Jefatura del Estado. Boletín Oficial del Estado (BOE) Madrid 163 p. 20.BOE-A-2020-5895-BOE.es (Legislación Consolidada). www.boe.es>Buscar.

${ }^{41}$ Constitución Española y la Constitución Europea (2006). Op. Cit., p.58.

Revista de Direito Brasileira | Florianólopis, SC | v. 25 | n. 10 | p. 459-472 | Jan./Abr. 2020
} 
causas de la venida de los turistas extranjeros a España, por tanto sería una responsabilidad civil o, penal en caso de la toma de medidas en los aeropuertos o, transportes marítimos como cruceros, como sería el ejemplo de los barcos que efectúan los transportes de viajeros desde el Continente Norte Africano tales como Marruecos o Argelia que unen a España. Por otra parte, es más clarificadora la Ley 33/2011, de 4 de octubre, General de Salud Pública ${ }^{42}$ en su artículo 52.1 que señala: "Tendrá la consideración de autoridad sanitaria estatal el titular del Ministerio de Sanidad, Política Social e Igualdad y, en el marco de sus respectivas funciones, los titulares de los órganos superiores y órganos directivos con responsabilidades en salud pública de dicho departamento ministerial con rango igual o superior al de Director General", por lo que será responsables subsidiarios el Director General de Sanidad de España, o su delegado en las Comunidades Autónomas, en caso de rebrote del Covid-19, por el turismo.

\section{CONCLUSIONES}

$1^{\circ}$. Tras vuelta a la normalidad en España han comenzado las personas ha salir a la calle lo que implica que muchos ciudadanos y ciudadanas han comenzado a visitar grande tiendas o, almacenes lo que implica que se les toma motorizadamente la toma de temperatura, sin previo consentimiento por lo cual, existe una vulnerabilidad de sus derechos por lo que, es importante que deban cancelar los ficheros automatizados de estas grandes empresas, dirigiéndose mediante comunicación al director de protección de datos de la Comunidad Autónoma o, en su caso a la atención del consumidor e, incluso podrán realizar las presuntas demandas tanto en el ámbito del derecho civil o, derecho penal.

$2^{\circ}$. Los entes públicos que realicen estos tipos de monitorización deben comunicarlo a los ciudadanos y ciudadanas, así como los ayuntamientos, colegios, por lo que no podrán conservar los ficheros automatizados, más de un mes como menciona el RGPD. Por otra parte, deben estar autorizados por Sanidad.

$3^{\circ}$. Los trabajadores y trabajadoras que se incorporen a sus puestos de trabajo, el empleador debe comunicarlo a ellos mediante escrito o, verbalmente para que estos tengan la opción de acceder o, incluso suprimir los datos de ellos en los ficheros automáticos de las empresas.

$4^{\circ}$ Los españoles o, extranjeros comunitarios o, extracomunitarios turistas o, de carácter humanitario que viajan en aeronaves o, barcos que se dediquen al desplazamiento de personas de un lugar a otro o, de un país a otro, dependerán de sanidad exterior la toma de temperatura, lo que implica que aunque la norma expresa que no se conservarán estos datos, si están obligados a rellenar un formulario que se ingresará en una base informatizada, por lo cual deberán tener acceso y, cancelar el formulario.

$5^{\circ}$. Desde el punto de vista de la normativa el concepto, toma de temperatura y visualización, de los pasajeros, me parece insuficiente, por lo cual debería de haberse realizado un Pcr, (análisis serológico), desde el punto de salida o, a la llegada del aeropuerto o, puerto. Lo que implica que el responsable civil o, penal será el Ministerio de Sanidad Español, en caso de rebrote de la pandemia por causa del turismo exterior.

$6^{\circ}$. Las Comunidades Autónomas solamente se dedicarán a auxiliar a los pasajeros enfermos que a la llegada de los aeropuertos o, puertos ante la toma de temperatura superen más de $37.5 \mathrm{C}$ e, incluso los turistas extracomunitarios que lleguen a España deberán tener un seguro privado para tal efecto a no ser, que el país de partida tenga algún convenio en materia de sanidad con España.

\footnotetext{
${ }^{42}$ Ley 33/2011, de 4 de octubre, General de Salud Pública I. Disposiciones generales. Jefatura del Estado. Boletín Oficial del Estado (BOE) Madrid 240.p.26. BOE-A-2011-15623-BOE.es (Legislación Consolidada). www.boe.es>Buscar.
} 


\section{REFERENCIAS}

$1^{\circ}$. Autores

López Calvo, José (2017) “Comentarios al Reglamento Europeo de Protección de Datos”. Editorial Jurídica Sepín Las Rozas (Madrid)

Fernández Burgueño, Pablo (2017) (No3) "La obligación de cifrado de la información en el Reglamento de Protección de datos” Editorial Woters Klumer. La Ley Las Rozas (Madrid).

Prieto Andrés, Antonio (2002). "La nueva Directiva europea sobre tratamiento de datos personales y la protección a la intimidad en el sector de las telecomunicaciones”. Diario La Ley № 5620 (Tomo 5), Año XXIII. Editorial La Ley Madrid (Las Rozas).

Salvador Sancho, Armando (1991). "Modalidades de ejercicio de la Competencia Estatal en Materia de Sanidad Exterior (Participación en la misma de las Comunidades Autónomas: Sentencia 252/88). Revista de Estudios de la Administración Local y Autonómica. Editorial INAP Madrid.

$2^{\circ}$. Constitución

Constitución Española y la Constitución Europea (2006). Edición Especial Consejo General de la Abogacía Española Editorial La Ley Madrid (Las Rozas).

$3^{\circ}$. Legislación Española

Ley Orgánica 3/2018, de 5 de diciembre de Protección de Datos Personales y garantía de derechos digitales. Boletín Oficial del Estado (BOE) Madrid. N. Boletín 294. http: //www.boe.es > buscar/act. docphp?id=BOE-A-2018-16673

Ley 33/2011, de 4 de octubre, General de Salud Pública I. Disposiciones generales. Jefatura del Estado. Boletín Oficial del Estado (BOE) Madrid 240. BOE-A-2011-15623-BOE.es (Legislación Consolidada). www.boe.es>Buscar.

Real Decreto-ley 21/2020, de 9 de junio, de medidas urgentes de prevención, contención y coordinación para hacer frente a la crisis sanitaria ocasionada por el COVID-19. I. Disposiciones generales. Jefatura del Estado. Boletín Oficial del Estado (BOE) Madrid 163.BOE-A-2020-5895BOE.es (Legislación Consolidada). www.boe.es>Buscar.

Real Decreto-ley 23/2020, de 23 de junio, por el que se aprueban medidas en materia de energía y en otros ámbitos para la reactivación económica. I. Disposiciones generales. Jefatura del Estado. Boletín Oficial del Estado (BOE) Madrid 175.p 4920. BOE-A-2020-6621-BOE.es. www.boe,es $>$ Calendario>24/06/2020

Orden SND/518/2020, de 11 de junio, por la que se regula la autorización de un programa piloto de apertura de corredores turísticos seguros en la Comunidad Autónoma de Illes Balears mediante el levantamiento parcial de los controles temporales en las fronteras interiores establecidos con motivo de la situación de crisis sanitaria ocasionada por el COVID-19. I. Disposiciones Generales. Ministerio de Sanidad. Boletín Oficial del Estado (BOE) Madrid. N. Boletín 165. BOE-A-2020-6024. www.boe.es>Buscar 
Resolución de 29 de junio de 2020, de la Dirección General de Salud Pública, Calidad e Innovación, relativa a los controles sanitarios a realizar en los puntos de entrada de España I. Disposiciones generales. Ministerio de Sanidad Boletín Oficial del Estado (BOE) Madrid.181. BOE-A-2020-6927.BOE.es www.boe,es>Calendario>01/07/2020

\section{$4^{\text {o. }}$ Jurisprudencia}

Tribunal Supremo (Sala Tercera de lo Contencioso-administrativo, Sección $4^{\text {a }}$ ) (Ponente: Xiol Ríos, Juan Antonio) (Sentencia de 27 de enero de 2003). Rec.388/2000. LA LEY 1114/2003.

Tribunal Supremo (Sala Tercera de lo Contencioso-administrativo, Sección 6a) (Ponente: Díez Picazo Giménez, Luís María) (Sentencia de 26 de enero de 2010) Rec.3371/2006.LA LEY431/2010

Tribunal Supremo (Sala Tercera de lo Contencioso-administrativo, Sección $4^{\text {a }}$ ) (Ponente: Menéndez Pérez, Segundo) (Sentencia de 10 de enero de 2012). Rec. 5243/2006. LA LEY463/2012

Tribunal Supremo (Sala Primera de lo Civil) (Ponente: Vela Torres, Pedro José) (sentencia 485/2016 de 14/ de julio) Rec.1805/2015. LA LEY 82421/2016

Tribunal Supremo (Sala Tercera de lo Contencioso-administrativo, Sección $1^{\text {a }}$ ) (Ponente: Román García, Fernando) (Auto del 15 de noviembre 2019). Rec.4739/2019. LA LEY 161731/2019

\section{$5^{\circ}$. Legislación Europea}

Carta Europea de Derechos Fundamentales de la Unión Europea (30/03/2012)

D.O.U.E.www.boe.es >doue

Reglamento (UE) 2016/679 del Parlamento Europeo y del Consejo de 27 de abril de 2016 relativo a la protección de las personas físicas en lo que respecta al tratamiento de datos personales y a la libre circulación de estos datos y por el que se deroga la Directiva 95/46/CE. (Reglamento general de protección de datos) https://www.boe.es/doue/2016/119/L000010088.pdf

Reglamento (UE) 2018/1139 del Parlamento Europeo y del Consejo (2018). Del 4 de julio. Diario de la Unión Europea. Bruselas. https://www.easa.europa.eu/documentlibrary/regulations/regulation-eu-20181139

6 . Legislación Internacional

Reglamento Sanitario Internacional (2008) Segunda edición. Editorial Organización Mundial de la Salud. Ginebra. Suiza

O.M.S. $\underline{\text { www.who.int }>\text { Acceso }}>$ Centro de prensa $>$ Detalles 